\title{
Closing the life cycle of the pharmaceutical ingredients from biological origin a green interface to waste management
}

\begin{abstract}
One of the greatest advantages of pharmaceutical biotechnology is the versatility. And although its approach to the production of drugs opens a plethora of green and sustainable possibilities, the generation of waste continues to represent a problem on a smaller scale, but it can be brought to near zero. This work proposes an alternative for recovery, treatment and reintroduction of waste in the production lines. Through the recovery of bacterial biomass residues, generated during the production of Active Pharmaceuticals Ingredients and excipients, we were able to extract concentrates of protein useful for the design of new culture media. We present 12 media designed with the processed waste, which have the same or better production yield than the commercial reference medium. In all cases, biomass production exceeds that obtained when growing under the same conditions in commercial media. This approach allowed us to solve a waste management problem, to reduce costs and to generate high added value products from waste. Its degree of innovation allowed us to protect the methods and prototypes in a patent application.
\end{abstract}

Keywords: pharmaceutical biotechnology, clean production, culture media design
Volume 2 Issue 4 - 2018

\author{
Moreno Maria Julieta," Gonzalez Exequiel," \\ Cerusico Nicolas Abel, Cabrera, Carla \\ Agostina Chavez-Jara, Romina Di Toto \\ Blessing, Lilian E Ramos, Alberto Nicolas \\ Sesto Cabral, Maria Eugenia \\ Laboratory of Biotechnology Pharmaceutical, Institute of \\ Biotechnology Pharmaceutical and Food-CONICET-UNT, \\ Argentina
}

Correspondence: Maria Eugenia Sesto Cabral, Laboratory of Biotechnology Pharmaceutical, Institute of Biotechnology Pharmaceutical and Food-CONICET-UNT,Argentina, Tel +54-38|4856596, Email eugenia.sestocabral@gmail.com

Received: July 3I, 2018 | Published: August 06, 2018

\section{Introduction}

Significant advantage over chemical synthesis is that biological ones takes less production time but can often use more expensive raw materials. Cost, is one of the main factors in economics of biotechnological production. Refined sugars and protein sources, although costly, are the most commonly used substrates for commercial production of metabolites by fermentation process. ${ }^{1}$ The trend towards environmental sustainability and development of renewable resources has significantly increased interest in the recovery of fermentation products, organic acids, and industrial chemicals. A range of products obtained by fermentation is expanding beyond the traditional highvolume and low-value compounds, like pharmaceuticals, competing with traditional synthetic production of commodity chemicals. As fermentation moves into higher values and low-volume chemicals, it becomes necessary to maximize efficiency and minimize costs and wastes to compete effectively against traditional options. Researchers and $\mathrm{I}+\mathrm{D}+\mathrm{i}$ teams from biotechnological industries must think about the end of the life cycle, before they create products. Our research group develops bacterial products for pharmaceutical industries, such as active pharmaceutical ingredients (API) and excipients also known as non-active pharmaceutical ingredients (NAPI). Our scaling up process was developed by thinking beyond end-of-pipe solutions by treating the problem of waste generation since the beginning of the research development. In a previous work we define our own critical process points. ${ }^{2}$ By replacing sugar and protein sources it was possible to maintain or increase the efficiency of production process. By reentering our own wastes in our process line, we manage to replace expensive constituents, maintaining LAPS antipathogenic properties. ${ }^{3}$ This paper presents our zero waste protocol, designed to reuse remnant biomass, transforming it into high added value products. In this manner, we use three critical waste production points and bacterial residual cells (BRC) which were treated by physical techniques for its content release. Three lines and bacteria from our research program were selected for this purpose, all these processes generate BRC. Bacteria are Pseudomonas fluorecens wild type used for nano cellulose production, Lactobacillus alimentarius wild type and Enterococcus faecium wild type, used for exopolysaccharides obtention. The three of them were used as microbial cell factories. ${ }^{3,4}$ The main objective in this work was to design a non-waste process production line, by transforming remnant biomass in higher values and low volume products. In addition, we expect to reintroduce the products obtained in the production lines as substitutes for the commercial protein sources, in order to create a green interface and to reduce costs.

\section{Methods}

\section{Bacterial strains and culture conditions}

Two strains of lactic acid bacteria were grown in Man Rogosa Sharpe (MRS-Britania-CABA-Argentina) broth and kept at $37^{\circ} \mathrm{C}$ : Lactobacillus alimentarius wild type and Enterococcus faecium wild type. A strain of Pseudomonas fluorecens wild type was grown in LB broth (Britania-C.A.B.A-Argentina) and kept at $25^{\circ} \mathrm{C}$.

\section{Residual Biomass reconversion}

Bacterial residual cells (BRC) isolated from all process were washed with saline solution and then centrifuged at $8000 \mathrm{rpm}$. for 10min (Arcano, 80-2b).

\section{Lysis process}

BRC pellet was previously submitted to 4 lysis methods. High pressure and high temperature method, with water, at $121^{\circ} \mathrm{C}$ for $15 \mathrm{~min}$, was the chosen one, for its higher proteins release concentration. 


\section{Chemical characterization}

For protein concentration assays using UV method were performed. The calibration curve was made by using bovine albumin as positive control and $\mathrm{pH}$ determination (pH Lutron).

\section{Physical characterization}

Dry pellet were obtained by placing $\mathrm{BRC}$ on a stove at $80^{\circ} \mathrm{C}$ for $12 \mathrm{~h}$. Physical characterizations were made from dry pellets: dry weight, humidity $\%$ and residual humidity (data no shown).

\section{Culture media design}

In order to obtain high value products, which also allow us to reduce the cost of production, 16 culture media were designed, by replacing $50 \%$ and $100 \%$ of proteins from commercial media. Table 1 shows composition of all media designed. When L. alimentarius residual cells were used, 4 media were designed and named BCM1 (Blessing Cabrera Moreno) to BCM4. When E. faecium residual cells were used, 5 media were designed and named CaGB1 (Cabrera Gonzalez Blessing) to CaGB5.When P. fluorecens residual cells were used, 3 media were designed and named GS1 (Gonzalez Sesto) to GS3.

Table I Media growth culture's composition

\begin{tabular}{|c|c|c|c|c|c|c|c|c|c|}
\hline Strains bacterial & $\begin{array}{l}\text { Media } \\
\text { designed* }\end{array}$ & $\begin{array}{l}\% \text { protein } \\
\text { replaced }\end{array}$ & $\begin{array}{l}\text { BRC } \\
\text { (g/L) }\end{array}$ & YE & BE & $\mathbf{B P}$ & Salt & Glucose & $\mathrm{pH}$ \\
\hline \multirow{4}{*}{ L. alimentarious } & BCMI & 50 & 2.5 & - & $x$ & $x$ & $x$ & $x$ & 6.51 \\
\hline & BCM2 & 100 & 5 & - & $\mathrm{x}$ & $x$ & $x$ & $x$ & 6.47 \\
\hline & ВСМ3 & 50 & 7.5 & - & - & $x$ & $x$ & $x$ & 6.31 \\
\hline & BCM4 & 50 & 10 & $x$ & - & - & $x$ & $x$ & 6.23 \\
\hline \multirow{5}{*}{ E. faecium } & CaGBI & 50 & 2.5 & - & $x$ & $x$ & $x$ & $x$ & 6.46 \\
\hline & CaGB2 & 100 & 5 & - & $x$ & $x$ & $x$ & $x$ & 6.37 \\
\hline & CaGB3 & 50 & 7.5 & - & - & $x$ & $x$ & $x$ & 6.32 \\
\hline & CaGB4 & 50 & 10 & $x$ & - & - & $x$ & $x$ & 6.18 \\
\hline & CaGB5 & 50 & 7.5 & - & $x$ & - & $x$ & $x$ & 6.35 \\
\hline \multirow{3}{*}{ P. fluorecens } & GSI & 50 & 2.5 & - & - & $x$ & $x$ & - & 6.52 \\
\hline & GS2 & 50 & 2.5 & $x$ & - & - & $x$ & - & 6.45 \\
\hline & GS3 & 100 & 7.5 & - & - & - & $x$ & - & 6 \\
\hline
\end{tabular}

\section{Bacterial growth in designed media}

In order to define applicability of all new media, we test growth kinetics by using MRS and LB media respectively as positive control. Media designed (BCM1 to BCM4, CaGB1 to CaGB5) were used as broth for Lactic Acid Bacteria (LAB) static cultivation. Lactic acid bacteria were grown for $12 \mathrm{~h}$ at $37^{\circ} \mathrm{C}$ in MRS media, then suspensions of $\mathrm{OD} 600 \approx 0.150$ were prepared using fresh medium as diluent and blank. P. fluorecens was grown for $24 \mathrm{~h}$ at $25^{\circ} \mathrm{C}$ in $\mathrm{LB}$ media, then suspensions of $\mathrm{OD} 600 \approx 0.150$ were prepared using fresh medium as diluent and blank. GS1 to GS3 media were tested as broth for static cultivation. In 96-well polystyrene microtiter plates (Costar Corning Inc. USA), $200 \mu \mathrm{L}$ of each media designed and controls were placed, and then $20 \mu \mathrm{L}$ of bacterial suspension were added. The plates were incubated for $12 \mathrm{~h}$ at $37^{\circ} \mathrm{C}$ and growth curves were obtained by measuring the OD600 once per hour in a microplate reader (Thermo Scientific Multi scan Go). Each curve was performed by quintuplicate and every point was expressed as mean $\pm \mathrm{SD}$.

\section{Biomolecules media composition}

To evaluate design media composition and compare against their controls, FTIR spectroscopy was used. FTIR spectroscopy is a novel tool widely employed to study organic composition of complex systems and allows a fast results obtaining without sample destruction. ${ }^{5,6}$ It was made a semiquantitative determination of the main biomolecules (proteins, lipids, carbohydrates). These biomolecules are used by strain as nutrient sources. For spectra acquisition, a PerkinElmer GX 1 spectrophotometer was used. $5 \mu \mathrm{L}$ of Media (designed and controls) were processed as liquid in $\mathrm{AgCl}$ circular window, dried under nitrogen flow previously. Spectra were collected with 64 scans and $4 \mathrm{~cm}^{-1}$ of resolution within mid-infrared range $\left(4000 \mathrm{~cm}^{-1}-400 \mathrm{~cm}^{-1}\right)$. Each media was processed twice and then averaged. Smoothing and base line correction were applied over spectra as pre-processing step to improve the signal to noise ratio. ${ }^{7}$ Obtained spectra were analyzed by OMNIC version 8.3 (Perkin Elmer, Waltham, MA) and Origin Pro 8.5.1 software (Electronic Arts, Redwood City, CA). According to the IR active vibration of the biomolecules bonds spectrum regions analyzed were: Lipids $\left(3000-2800 \mathrm{~cm}^{-1}\right)$, Ester bonds $(1770$ $\left.1720 \mathrm{~cm}^{-1}\right)$, Amide I $\left(1700-1600 \mathrm{~cm}^{-1}\right)$, Amide II $\left(1600-1450 \mathrm{~cm}^{-1}\right)$, Carbohydrates and polysaccharides $\left(1200-900 \mathrm{~cm}^{-1}\right) .8$ Amide I and II are directly related with protein composition and absorbance from each spectral region is correlated to biomolecule composition, while lipids and ester bonds regions indicate bacterial bio membrane presence. ${ }^{7,8}$ 


\section{Result and discussion}

Productive activity is a fundamental column in country's economic development, also is one of the main factors of unsustainability. One of the greatest advantages of pharmaceutical biotechnology is the versatility. And although its approach to the production of drugs opens a plethora of green and sustainable possibilities, the generation of waste continues to represent a problem on a smaller scale, but it can be brought to near zero. Waste production and natural resources consume diminishing sustainability and economic growth. We are seeking to improve our own process and to insert Clean Production in our production lines. When protein concentration in RBC was determinated (Figure 1), non-significant differences were found between lysates. Also, they present values $10 \%$ higher than other lysates presented as protein supplementary. ${ }^{9,10}$ By using protein concentration as indicator, 12 media were designed and tested for growing compared to commercial media. In all cases, protein sources were replaced for RBC. Table 1 shows all media designed by using RBC from lactic acid bacteria and P. fluorescens. 12 media were designed and tested for bacterial growth. Figure 2 shows Lactobacillus alimentarius growth in four media designed (BCM1 to BCM4) compared to commercial media. Significant differences were found in $\mathrm{L}$. alimentarius growth when BCM1, BCM2, BCM3 and BCM4 were compared to MRS In all cases, $\mathrm{L}$. alimentarius growth was consistently superior, being $20.53 \%$ higher for $\mathrm{BCM} 1,30.22 \%$ higher for $\mathrm{BCM} 2,27.48 \%$ higher for BCM3, and $30.28 \%$ higher for BCM4. In the analysis by FTIR spectroscopy of the media composition we could conclude that RBC increases the lipid and carbohydrate sources as it can see in the Lipids and Carbohydrate spectral regions for BCM 1 to BCM 4. While the increases of protein quantity were only observed in BCM1 to 3 Figure 5. Figure 3 shows Enterococcus faecium growth in five media designed (CaGB1 to CaGB5) compared to commercial media MRS. Significant differences were found in E. faecium growth. In all cases, we observed much better growing when we use our designed media: $14.47 \%$ higher for $\mathrm{CaBG} 1,13.76 \%$ for $\mathrm{CaBG} 2,12.00 \%$ for $\mathrm{CaBG} 3$, $15.68 \%$ for $\mathrm{CaBG} 4,3.34 \%$ for CaBG5. As occurred with $\mathrm{BCM}$ design media, RBC increases the lipids and carbohydrate sources for CaGB1 to CaGB5. Only CaGB1 and CaGB2 increase the quantity of protein Figure 5. Berg et al. suggest that the presence of peptides in yeast extract enhances growth of Lactobacillus. ${ }^{11}$ The nutritional requirements have been discussed by Rogosa et al. They emphasized the importance of amino acids and vitamins for the growth of Lactobacillus. 12Amrane and Prigent and Nancib et al. explained the contributions of $\mathrm{B}$ vitamins, purine and pyrimidine bases in the medium for the growth of Lactobacillus. ${ }^{13,14}$ Our results show that, these necessities could be completely supplemented by using RBC. Figure 4 shows Pseudomonas fluorecens growth in three media designed (GS1 to GS3) compared to commercial media Luria Bertani broth. Significant differences were found in P. fluorescens growth. In all cases, we observed much better growing when we use our designed media: $32 \%$ higher for GS1, $9.67 \%$ for GS2, 35\% for GS3. This increase in the concentration of biomass allows us to infer an increase in the cellulose production by Pseudomonas fluorescens. It is reported that increases in bacterial growth generate more exopolysaccharides. ${ }^{15}$ RCB contributes increasing lipids and carbohydrates for GS1 to GS3 Figure 5. Frequency displacement observed in AMIDE regions for GS1 to GS3 respect from LB control, indicates a change of protein sources in the media composition, and could be responsible for the higher growing rates obtained in the design media Figure 5.

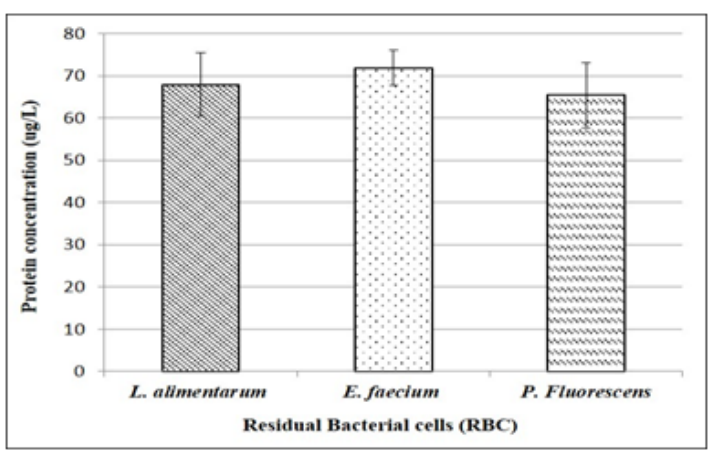

Figure I Protein concentration for RBC from $L$ alimentarius, $E$ faecium and $\mathrm{P}$ fluorecens, measured as ug/L by using bovine albumin as positive control.

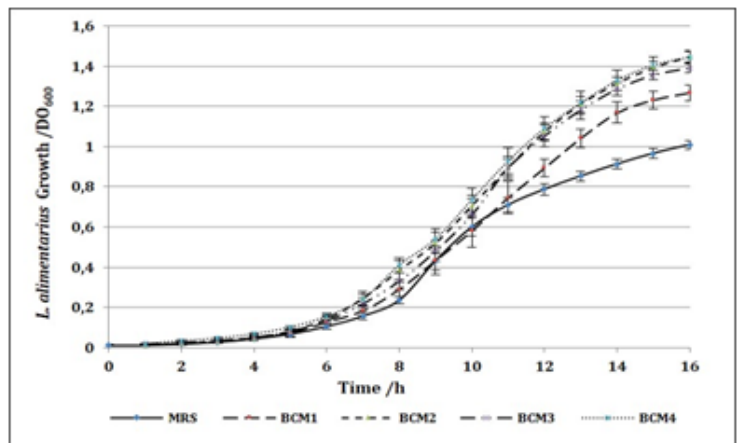

Figure $2 \mathrm{~L}$ alimentarum growth measured as OD600 vs time in media samples BCMI, BCM2, BCM3 and BCM4 and MRS commercial media as positive control.

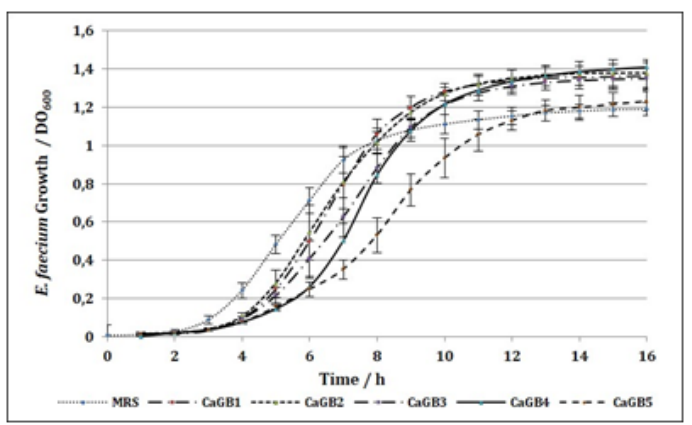

Figure $3 \mathrm{E}$ faecium growth measured as OD600 vs time in media samples: CaGBI, CaGB2, CaGB3, CagB4, CaGB5 and MRS commercial media as positive control.

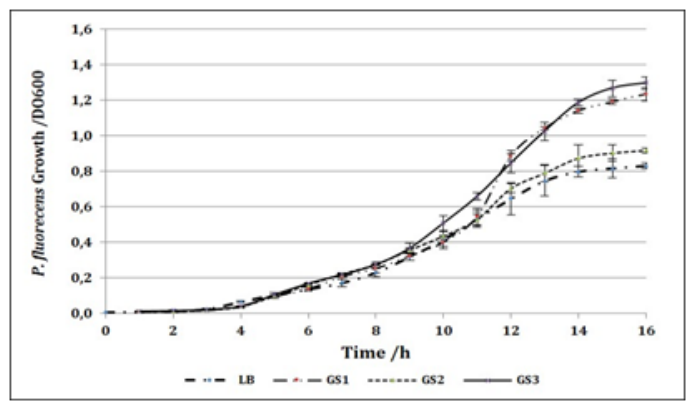

Figure $4 \mathrm{P}$ fluorecens growth measured as OD600 vs time in media samples: GSI, GS2, GS3 and LB commercial media as positive control. 


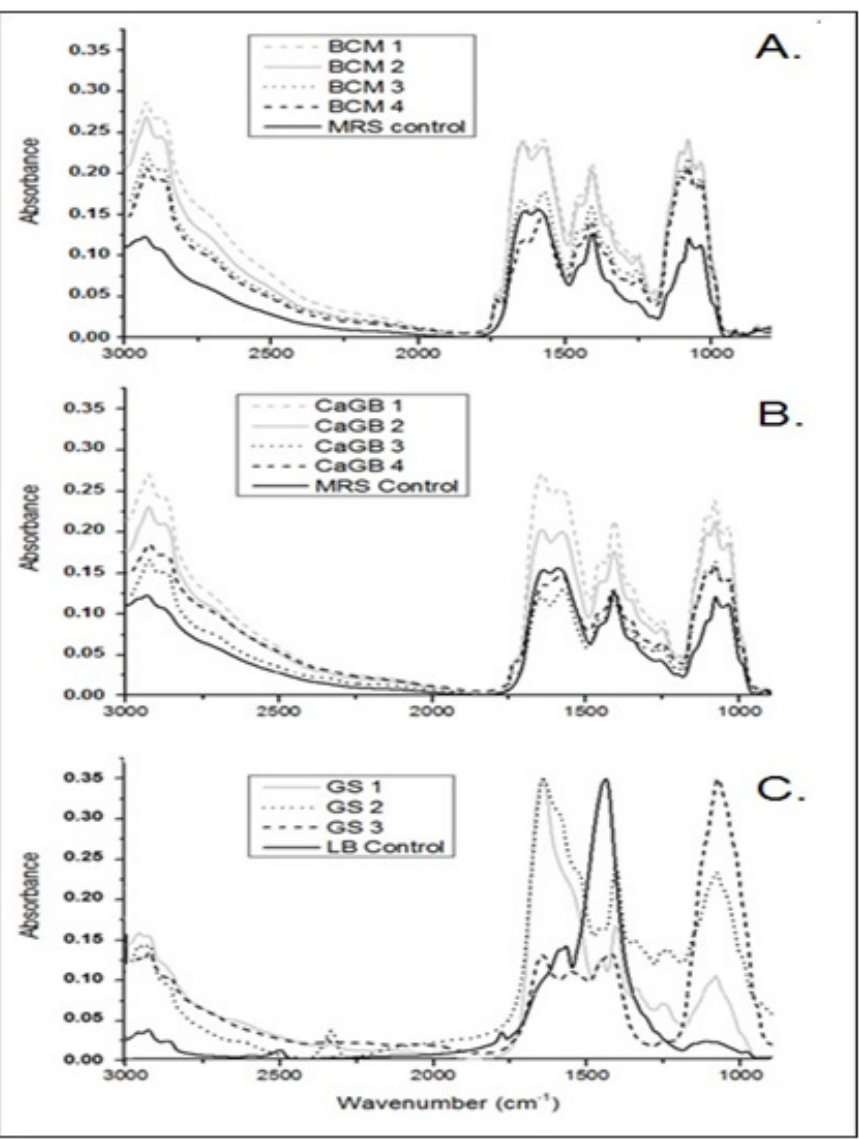

Figure 5 FTIR Spectra of design media and controls.A. Shows BCM I to BCM 4Vs. MRS Control. B. Shows CaGB I to CaGB 4Vs. MRS Control and C. Shows GS I to GS 3 Vs. LB control.

\section{Conclusion}

We achieve our main purpose of design a non-waste process production line, by transforming remnant biomass in higher values products. We develop 12 growth media, and its innovation degree allow as also, there intellectual protection on a patent INPI ARN20170102314. In addition, we will reintroduce the products obtained in the production lines as substitutes for the commercial protein and carbohydrate sources, in order to create a green interface and to reduce costs. We achieve our main purpose to minimize environmental damage, to use resources more efficiently; and to increase business profitability and competitiveness.

\section{Acknowledgements}

National Agency for Scientific and Technological Promotion (ANPCyT), Ministry of Science and Technology (MiNCyT), National Council for Scientific and Technical Research (CONICET). Moreno Maria Julieta \& Gonzalez Exequiel are equal contributors of my article.

\section{Conflict of interest}

Authors declare there is no conflict of interest.

\section{References}

1. Altaf MD, Naveena BJ, Venkateshwar M, et al. Single step fermentation of starch to L (+) lactic acid by Lactobacillus amylophilus GV6 in SSF using inexpensive nitrogen sources to replace peptone and yeast extractoptimization by RSM. Process Biochem. 2006;41(2):465-472.

2. Moreno MJ, Cabrera CA, González E. Harmless Bacterial by Products for Chronic Wound Treatment. A Clean Production Experience. International journal of pharmaceutical research and analysis. 2018;3(1):1-11.

3. Sesto Cabral ME, Ramos AN, Macedo AJ, et al. Formulation and quality control of semisolid containing harmless bacteria by-products: chronic wounds pro-healing activity. Pharm Dev Technol. 2015;20:911-918.

4. Cabrera CA, Ramos AN, Loandos $\mathrm{MH}$, et al. Novel topical formulation for ischemic chronic wounds. Technological design, quality control and safety evaluation. Pharm Dev Techno. 2016;21(4):399-404

5. Yang H, Yang S, Kong J, et al. Obtaining information about protein secondary structures in aqueous solution using Fourier transform IR spectroscopy. Nat Protoc. 2015;10(3):382-396.

6. Liu K, Shaw RA, Man A, et al. Reagent-free, Simultaneous Determination of Serum Cholesterol in HDL and LDL by Infrared Spectroscopy. Clin Chem. 2002;48(3):499-506.

7. Baker M, Trevisan J, Bassan P, et al. Using Fourier transform IR spectroscopy to analyze. Nat protoc. 2014;9(8):1171-1191.

8. Cerusico N, Aybar JP, Lopez S et al. FTIR spectroscopy of chronic venous leg ulcer exudates: an approach to spectral healing markers identificamtion. Analyst. 2018;143(7):1583-1592.

9. Wee YJ, Kim HO, Yun JS, et al. Pilot-scale lactic acid production via batch culturing of Lactobacillus sp. RKY2 using corn steep liquor as a nitrogen source. Food Technology and biotechnology. 2006;44(2):293-298.

10. Afifi MM. Enhancement of Lactic Acid Production by Utilizing Liquid Potato Wastes. Biological Chemistry. 2011;5(2):91-102.

11. Berg RW, Sandine WE, Anderson AW. Identification of a growth stimulant for Lactobacillus san francisco. Appl Environ Microbiol. 1981;42(25):786-788.

12. Rogosa M, Franklin JG, Perry KD. Correlation of the vitamin requirements with cultural and biochemical characters of Lactobacillus sp. J Gen Microbiol. 1961;25:473-482.

13. Amrane A, Prigent Y. Lactic-acid production from lactose in batch culture-Analysis of the data with the help of a mathematical modelRelevance for nitrogen-source and preculture assessment. Appl Microbiol Biotechnol. 1994;40(5):644-649.

14. Nancib A, Nancib N, Meziane-Cherif D, et al. Joint effect of nitrogen sources and B vitamin supplementation of date juice on lactic acid production by Lactobacillus casei subsp. rhamnosus Bioresour Technol. 2005;96(1):63-67.

15. Angelaalincy M, Senthilkumar N, Karpagam R, et al. Enhanced Extracellular Polysaccharide Production and Self-Sustainable Electricity Generation for PAMFCs by Scenedesmus sp. SB1 ACS Omega. 2017;2(7):3754-3765 